\title{
Electrochromic Devices Deposited on Low-Temperature Plastics by Plasma-Enhanced Chemical Vapor Deposition
}

\author{
DOE Award \# DE-FG36-04GO14328 \\ Final Report \\ Covering October 1, 2004 - September 15, 2005 \\ Joshua J. Robbins \\ CMD Research, LLC \\ $11099^{\text {th }}$ St., \#1 \\ Golden, CO 80401 \\ Ph: (720)771-6997 \\ Fax: (303)278-4120 \\ e-mail: jrobbins@cmdresearch.com
}

\section{Project Team:}

Technical Project Officer: Deborah Weems, 303-275-4957, Debbie.Weems@go.doe.gov Project Monitor: Chad Schell, 303-275-4729, chad.schell@go.doe.gov 


\section{Electrochromic Devices Deposited on Low-Temperature Plastics by Plasma-Enhanced Chemical Vapor Deposition}

Final report for contract \#DE-FG36-04GO14328

\section{Executive Summary}

Electrochromic windows have been identified by the Basic energy Sciences Advisory committee as an important technology for the reduction of energy spent on heating and cooling in residential and commercial buildings. Electrochromic devices have the ability to reversibly alter their optical properties in response to a small electric field. By blocking ultraviolet and infrared radiation, while modulating the incoming visible radiation, electrochromics could reduce energy consumption by several Quads per year. This amounts to several percent of the total annual national energy expenditures.

The purpose of this project was to demonstrate proof of concept for using plasmaenhanced chemical vapor depostion (PECVD) for depositing all five layers necessary for full electrochromic devices, as an alternative to sputtering techniques. The overall goal is to produce electrochromic devices on flexible polymer substrates using PECVD to significantly reduce the cost of the final product.

We have successfully deposited all of the films necessary for a complete electrochromic devices using PECVD. The electrochromic layer, $\mathrm{WO}_{3}$, displayed excellent change in visible transmission with good switching times. The storage layer, $\mathrm{V}_{2} \mathrm{O}_{5}$, exhibited a high storage capacity and good clear state transmission. The electrolyte, $\mathrm{Ta}_{2} \mathrm{O}_{5}$, was shown to functional with good electrical resistivity to go along with the ability to transfer Li ions. There were issues with leakage over larger areas, which can be address with further process development. We developed a process to deposit ZnO:Ga with a sheet resistance of $<50 \Omega /$ sq. with $>90 \%$ transmission. Although we were not able to deposit on polymers due to the temperatures required in combination with the inverted position of our substrates. Two types of full devices were produced. Devices with $\mathrm{Ta}_{2} \mathrm{O}_{5}$ were shown to be functional using small aluminum dots as the top contact. The polymer electrolyte devices were shown to have a clear state transmission of $69 \%$ and a darkened state transmission $11 \%$. These un-optimized devices compared well with commercially available products, which have a stated clear transmission of $59 \%$ and dark transmission of $4 \%$.

The PECVD oxides have displayed advantages over films produced by sputtering. The first advantage is that deposition rates were significantly higher than typical sputtering rates. Rates of $100 \mathrm{~nm} / \mathrm{min}$ were achieved for $\mathrm{WO}_{3}$, and rates of $50 \mathrm{~nm} / \mathrm{min}$ produced quality $\mathrm{V}_{2} \mathrm{O}_{5}$ and $\mathrm{Ta}_{2} \mathrm{O}_{5}$ films. Faster rates will produce a significant reduction in cost due to higher throughput. Another advantage was that films were less dense than those produced by sputtering as reported in the literature. This leads to high diffusion coefficients and fast switching times. Also less dense films have been shown to produce larger contrast ratios in $\mathrm{WO}_{3}$ and larger storage capacity in $\mathrm{V}_{2} \mathrm{O}_{5}$.

From the data collected in this category 1 project we have shown that PECVD is feasible and beneficial for the deposition of working layers for electrochromic devices. These results and the lessons learned can be applied toward deposition on polymers and equipment scale-up in future work. 


\section{Electrochromic Devices Deposited on Low-Temperature Plastics by Plasma-Enhanced Chemical Vapor Deposition}

Final report for contract \#DE-FG36-04GO14328

\section{Project Summary}

\section{Project Objectives}

We identified 5 main tasks to be completed by the end of this category 1 study. The tasks were as follows:

1) Fabrication of 2 plasma-enhanced chemical vapor deposition chambers.

2) Deposition and characterization of electrochromic $\left(\mathrm{WO}_{3}\right)$ and storage layer $\left(\mathrm{V}_{2} \mathrm{O}_{5}\right)$.

3) Development of low-temperature PECVD process for gallium doped zinc oxide and evaluation for use as contact layers.

4) Development of PECVD process for tantalum oxide deposition as an electrolyte layer.

5) Fabrication and evaluation of full electrochromic devices.

\section{PECVD System Fabrication}

The first objective of this project was to design and construct two plasmaenhanced chemical vapor deposition (PECVD) chambers capable of depositing all 5 layers necessary for an electrochromic device. The chambers were designed to handle the variety of organo-metallic and metal halide precursors required, and provide the ability to individually adjust all of the main control parameters necessary of the process development of these oxides. The main control parameters include chamber pressure, total flowrate, gas composition, rf power, electrode spacing, and substrate temperature. A photograph and detailed diagram of the main chamber is provided in Figure 1. The chambers are approximately 14" in diameter and 12” in height. The 6” diameter showerhead serves as the powered electrode, while the rest of the chamber is grounded. Substrates are clamped to the top electrode in an inverted position.

The gas manifold was designed to allow independent control of all deposition gases and prevent gas mixing until the desired point. Industrial-grade $\mathrm{Ar}, \mathrm{H}_{2}$, and $\mathrm{O}_{2}$ stored in gas cylinders were used and flowrates were controlled using mass flow controllers (MFCs). Tungsten hexafluoride $\left(\mathrm{WF}_{6}\right)$ and Vanaduim oxytrichloride $\left(\mathrm{VOCl}_{3}\right)$ flowrates were also controlled by MFCs. Diethyl zinc [DEZ - $\mathrm{Zn}\left(\mathrm{C}_{2} \mathrm{H}_{5}\right)_{2}$ ] and trimethyl gallium [TMG - $\mathrm{Ga}\left(\mathrm{CH}_{3}\right)_{3}$ ] flowrates must be controlled by needle valve due to the occurrence of thermal breakdown inside the MFCs. Supplying Tantalum ethoxide $\left[\mathrm{Ta}\left(\mathrm{OC}_{2} \mathrm{H}_{5}\right)_{5}\right]$ presents a special challenge, due to its low vapor pressure at room temperature, and a bubbler system was used.

The chamber design was successful in depositing all oxides required for electrochromic device evaluation on a small scale. The wide parameter space available 
allowed for effective process development in order to produce films with a range of properties.
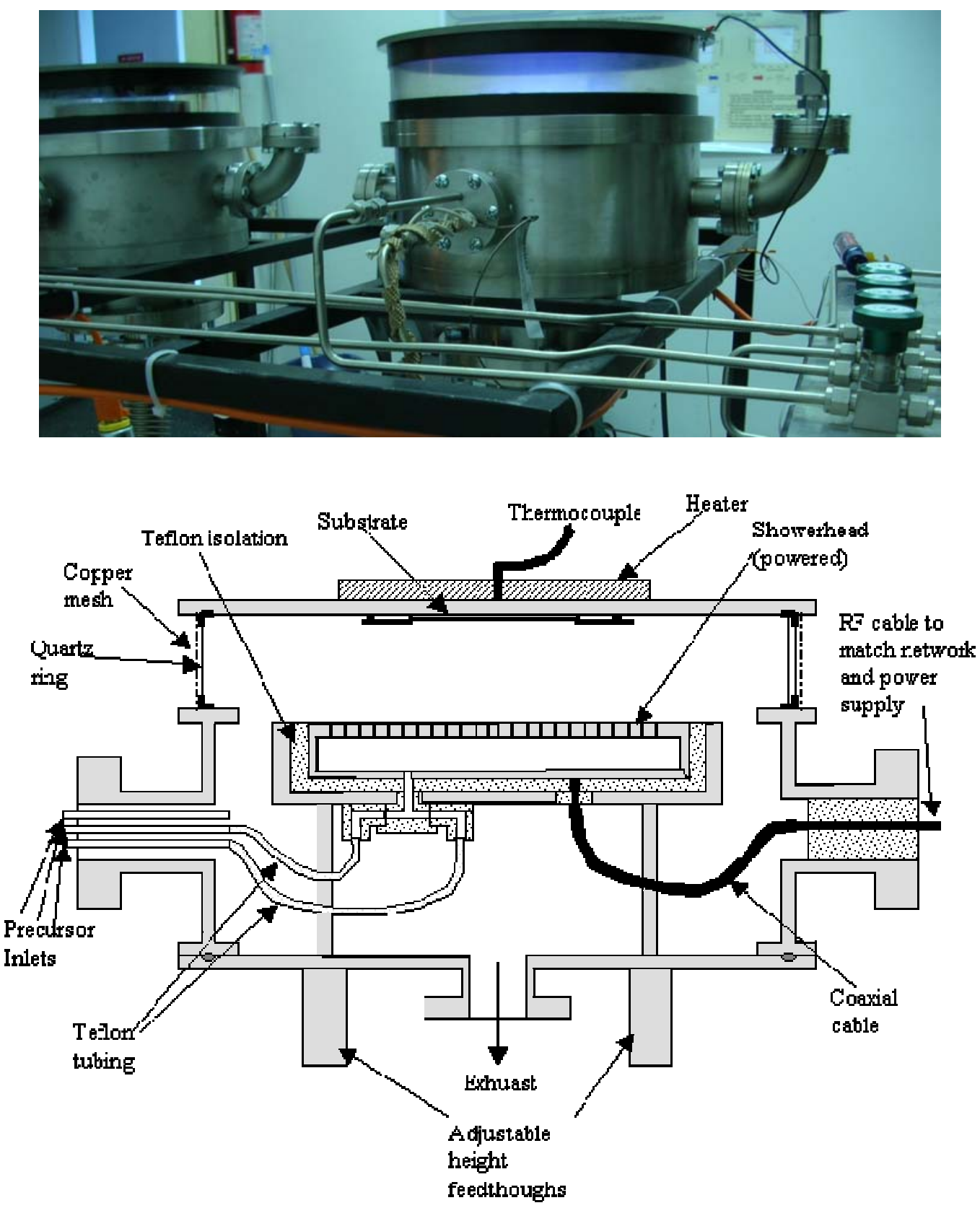

Figure 1: Photograph and detailed schematic of deposition chambers. 


\section{Deposition of Electrochromic and Storage Layers}

\section{Tungsten Oxide}

PECVD of tungsten oxide was accomplished by the incorporation of three gaseous precursors: tungsten hexafluoride $\left(\mathrm{WF}_{6}\right)$, oxygen, and hydrogen. The plasma effectively disassociates these molecular precursors down to reactive intermediates and monatomics. In particular, the PECVD process frees large amounts of reactive fluorine from the disassociation of the $\mathrm{WF}_{6}$ precursor. These fluorine atoms can simultaneously etch the growing $\mathrm{WO}_{3}$ film and hinder growth rates. Hydrogen is added to the plasma to scavenge the reactive fluorine and maximize growth rates. The process can be summarized by the following chemical reaction:

$$
\mathrm{WF}_{6}+\mathrm{O}_{2}+\mathrm{H}_{2} \rightarrow \mathrm{WO}_{3}+\mathrm{HF}+\text { excess } \mathrm{H}_{2}, \mathrm{O}_{2}, \mathrm{OH} \text {, ect. }
$$

During this study, we found $\mathrm{WO}_{3}$ deposition rates were maximized with Hydrogen to $\mathrm{WF}_{6}$ gas ratios of $4: 1$. Under the following conditions the $\mathrm{WO}_{3}$ rate was found to be 100 $\mathrm{nm} / \mathrm{min}$.

$\begin{array}{lcc}W_{6} & 4 & \text { sccm } \\ \mathrm{O}_{2} & 68 & \text { sccm } \\ \mathrm{H}_{2} & 16 & \text { sccm } \\ & & \\ \text { Pressure } & 200 & \text { mTorr } \\ \text { Power } & 150 & \text { Watts }\end{array}$

The substrate is not intentionally heated and the process is run at room temperature. However, some heating of the substrate due to the plasma processing occurs, but was not observed to increase beyond $40^{\circ} \mathrm{C}$.

The deposited films were evaluated using an electrochemical cell. The cell consists of a working, counter and reference electrode. The $\mathrm{WO}_{3}$ film serves as the working electrode and a potential may be set by the potentiostat in reference to the reference electrode. The current is recorded at the counter electrode. The electrochemical reaction occurring in the cell is the double injection of both ions and electrons into the WO3 film in accordance to the following reaction:

$$
\mathrm{WO}_{3}+\mathrm{xLi}^{+}+\mathrm{xe}^{-} \leftarrow \rightarrow \mathrm{Li}_{\mathrm{x}} \mathrm{WO}_{3}
$$

Where $\mathrm{x}$ is referred to as the intercalation extent and is set by the applied potential.

The amorphous $\mathrm{WO}_{3}$ films deposited displayed excellent responses for properties desired for an electrochromic layer. Figure 2 gives percent transmission as a function of intercalation extent of a $500 \mathrm{~nm}$ thick film with $\mathrm{x}$ varying between $\mathrm{x}=0.0$ to $\mathrm{x}=0.39$. Higher wavelengths are very sensitive to increased in ion insertion, while the wavelength range between 350 and $500 \mathrm{~nm}$ is gradually reduced with intercalation. Overall, the films show a high deintercalated/clear state transmission. Figure 3 visibly depicts the change in transmission shown graphically in Figure 2. Provided in Table I are the average visible transmissions (400 - $800 \mathrm{~nm}$ ) obtained after several different applied potentials. After 
applying a potential of -1.0 volt for 60 seconds the $500 \mathrm{~nm}$ thick film obtains an intercalation extent of 0.25 and an average transmission of $6.6 \%$.

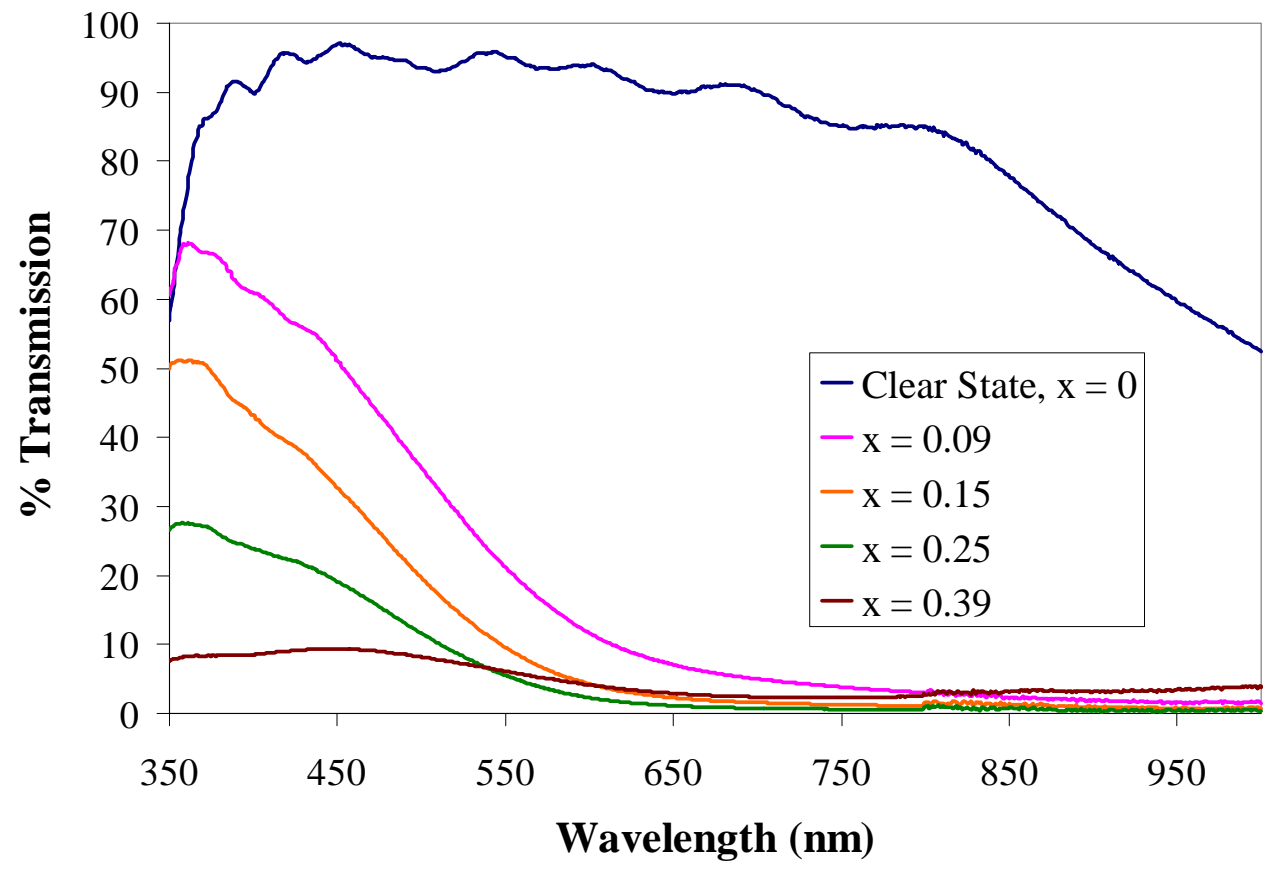

Figure 2: Transmission of $500 \mathrm{~nm}$ thick film of $\mathrm{WO}_{3}$ at various intercalation extents.

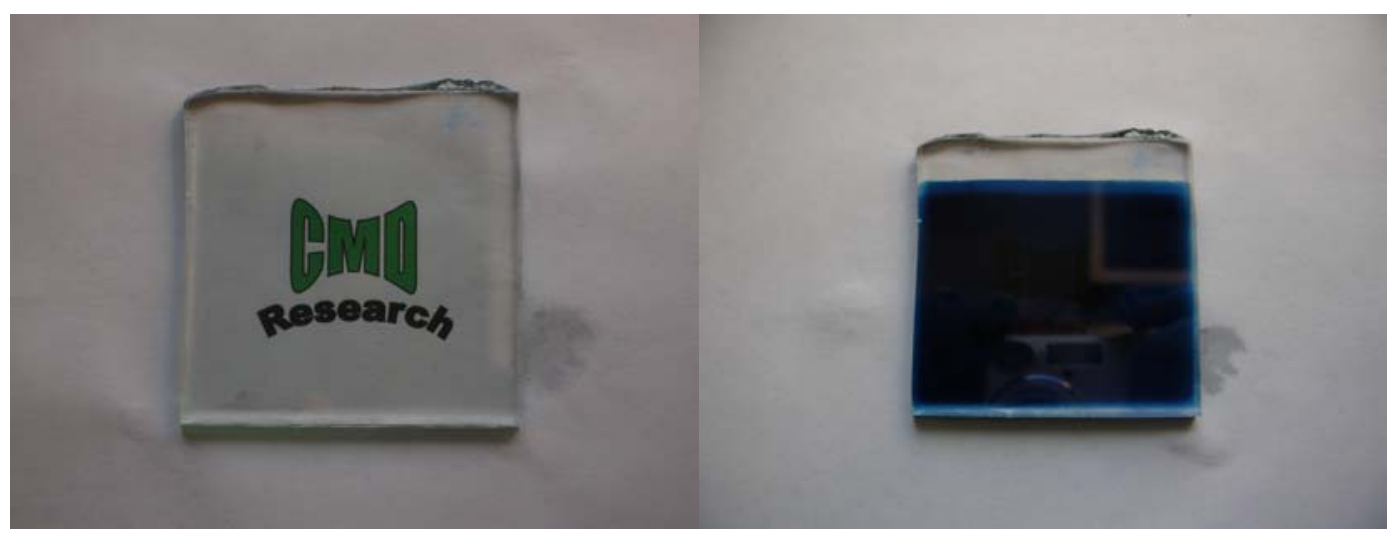

Figure 3: Photographs of $\mathrm{WO}_{3}$ in clear and darkened states. 


\begin{tabular}{|c|c|c|c|c|}
\hline $\begin{array}{c}\text { Intercalation } \\
\text { Voltage [V] }\end{array}$ & $\begin{array}{c}\text { Intercalation } \\
\text { Time [sec] }\end{array}$ & $\begin{array}{c}\text { Intercalation } \\
\text { Extent, } x\end{array}$ & $\begin{array}{c}\text { Charge } \\
{\left[\mathrm{mC}^{2} / \mathrm{cm}^{2}\right]}\end{array}$ & $\begin{array}{c}\text { Avg. \% Transmission } \\
(400-800 \mathrm{~nm})\end{array}$ \\
\hline 0 & 0 & 0 & 0 & 91.6 \\
-1 & 10 & 0.09 & 7.4 & 20.8 \\
-1 & 20 & 0.15 & 17.6 & 11.6 \\
-1 & 60 & 0.25 & 28.3 & 6.6 \\
-1.5 & 60 & 0.39 & 45.0 & 5.1 \\
\hline
\end{tabular}

Table I: Intercalation response of $\mathrm{Li}_{\mathrm{x}} \mathrm{WO}_{3}$.

To demonstrate the stable reversibility of the films, the $\mathrm{WO}_{3}$ films were cycled in a liquid electrolyte between -1.0 and $+1.0 \mathrm{~V}$ at a sweep rate of $50 \mathrm{mV} / \mathrm{second}$. Figure 4 shows the current response in time to this continued cycling. This graph shows the current due to ions moving into and out of the film in response to the changing voltage. As the film is cycled, the same response is recorded, thus no change in performance is observed with cycling. For the total 20 cycles tested no change in film performance was observed.

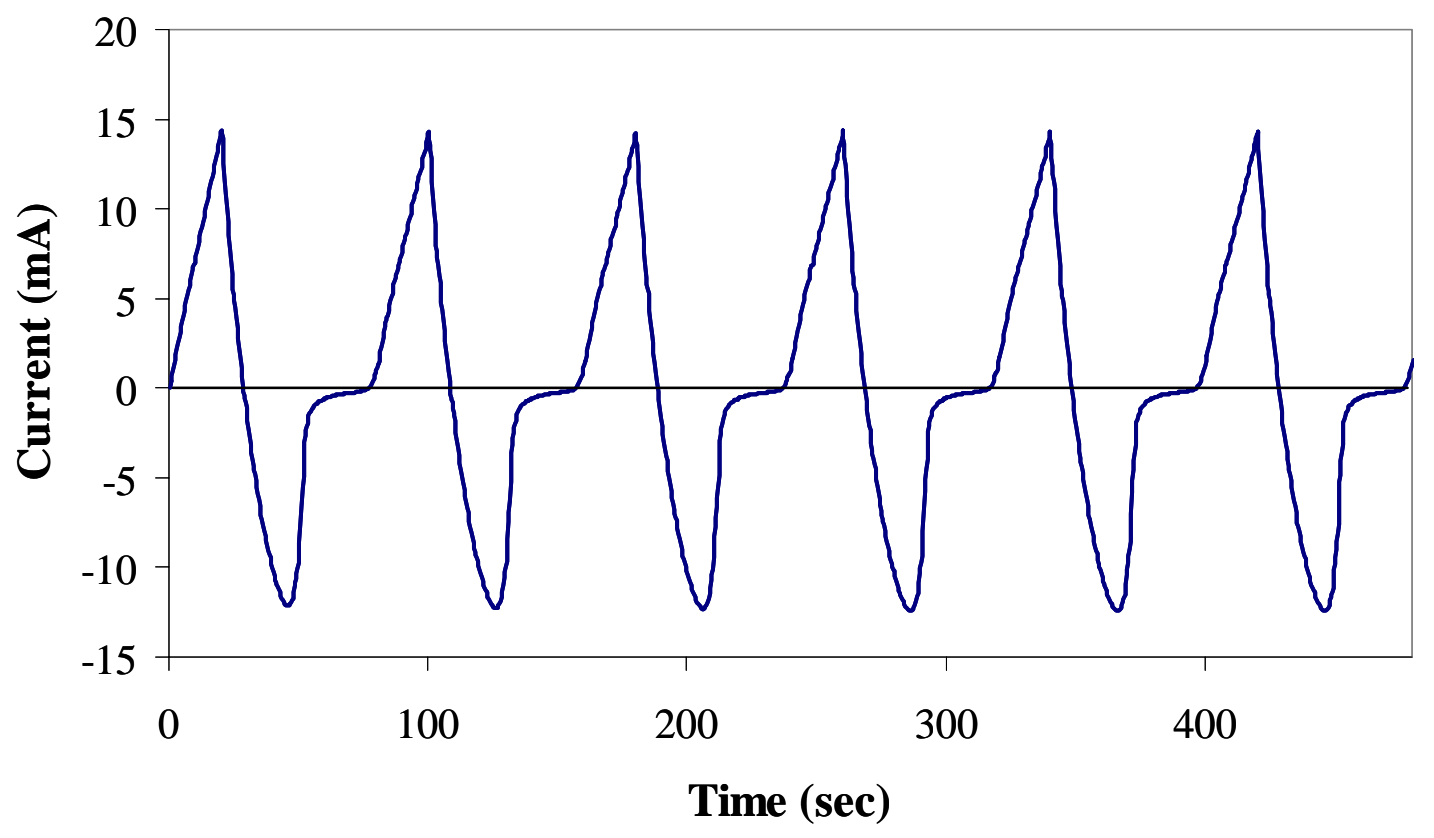

Figure 4: Current response to the cycling of $\mathrm{WO}_{3}$ from $-1 \mathrm{~V}$ to $+1 \mathrm{~V}$ at a sweep rate of $50 \mathrm{mV} / \mathrm{sec}$.

Overall, we have shown that PECVD is a viable process for the production of $\mathrm{WO}_{3}$ films. The high growth rate of $100 \mathrm{~nm} / \mathrm{min}$ observed here is favorable to the scaleup and production of electrochromic stacks. Individual films evaluated in a liquid 
electrolyte showed excellent change in transmission for good switching times. Initial test show reversibility between transmission states, however future testing on cycle life will be required.

\section{Vanadium Oxide}

PECVD of vanadium oxide can be carried out through the plasma decomposition of oxygen and $\mathrm{VOCl}_{3}$. For this system the growth rate was examined as a function of power and pressure. Figure 5 depicts the growth rate as a function of power at the given chamber pressures of $125 \mathrm{mT}, 200 \mathrm{mT}$, and $400 \mathrm{mT}$. Precursor flow rates of $\mathrm{VOCl}_{3}$ and $\mathrm{O}_{2}$ were held constant; additionally the electrode gap was set to $13 / 8$ ”. The rate is found to decrease with both increasing pressure and power. While higher rates are achievable the rate of vanadium oxide deposition was kept between 10 and $45 \mathrm{~nm} / \mathrm{min}$ to ensure that extremely thin films, between 100 and 150nm, could be reliably reproduced.

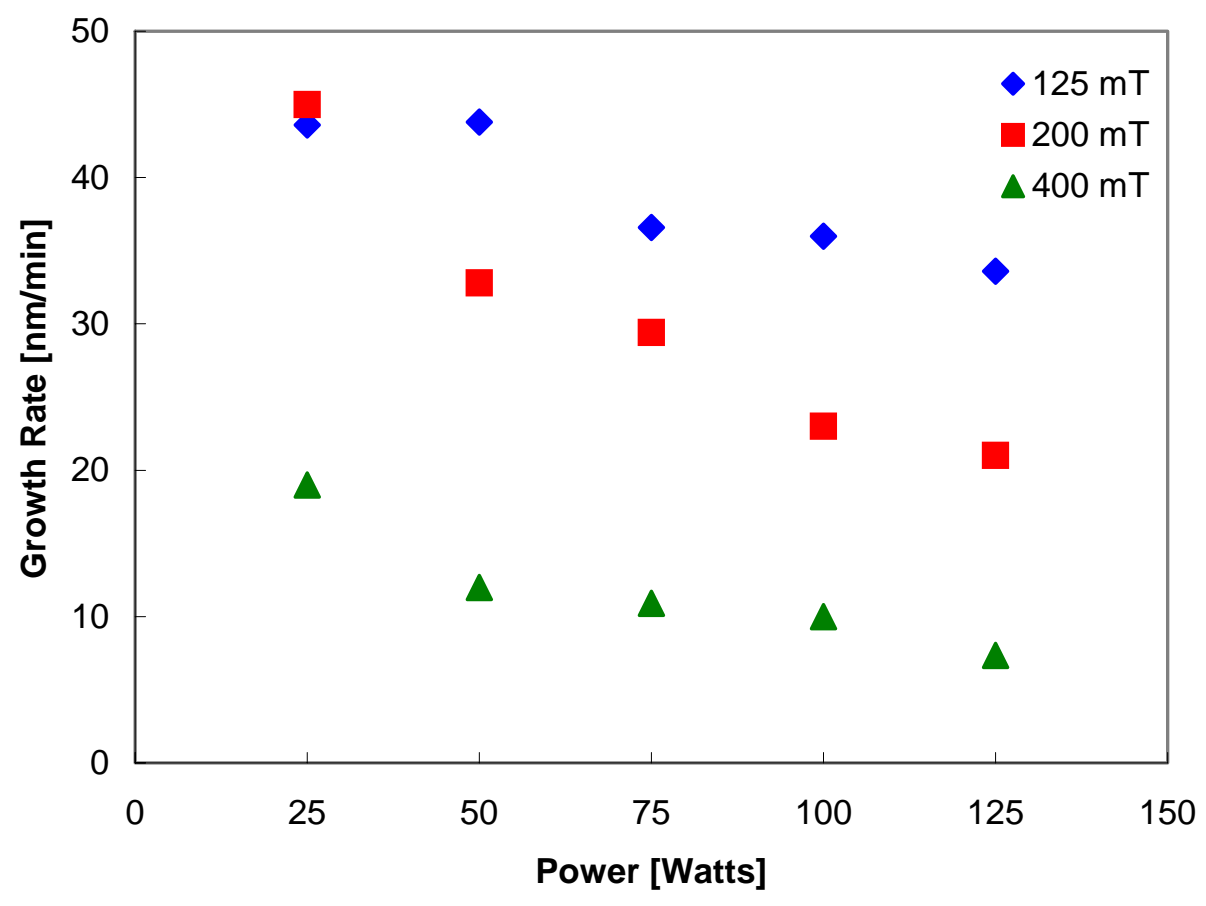

Figure 5: Growth Rate of vanadium oxide as a function of power and chamber pressure.

Figure 6 depicts the change in transmission as a function of inserted charge for a $100 \mathrm{~nm}$ thick film of vanadium oxide. Initial insertion of small amounts of $\mathrm{Li}^{+}$ions increased the overall transmission and the film changed from a pale yellow to clear. Further increasing of the intercalation extent did not affect the optical properties. The films have a reversible storage capacity of $\mathrm{x}>2\left(\mathrm{Li}_{\mathrm{x}} \mathrm{V}_{2} \mathrm{O}_{5}\right)$, and thus can remain very thin while maintaining the $\mathrm{Li}$ concentration necessary for optical switching in $\mathrm{WO}_{3}$. 


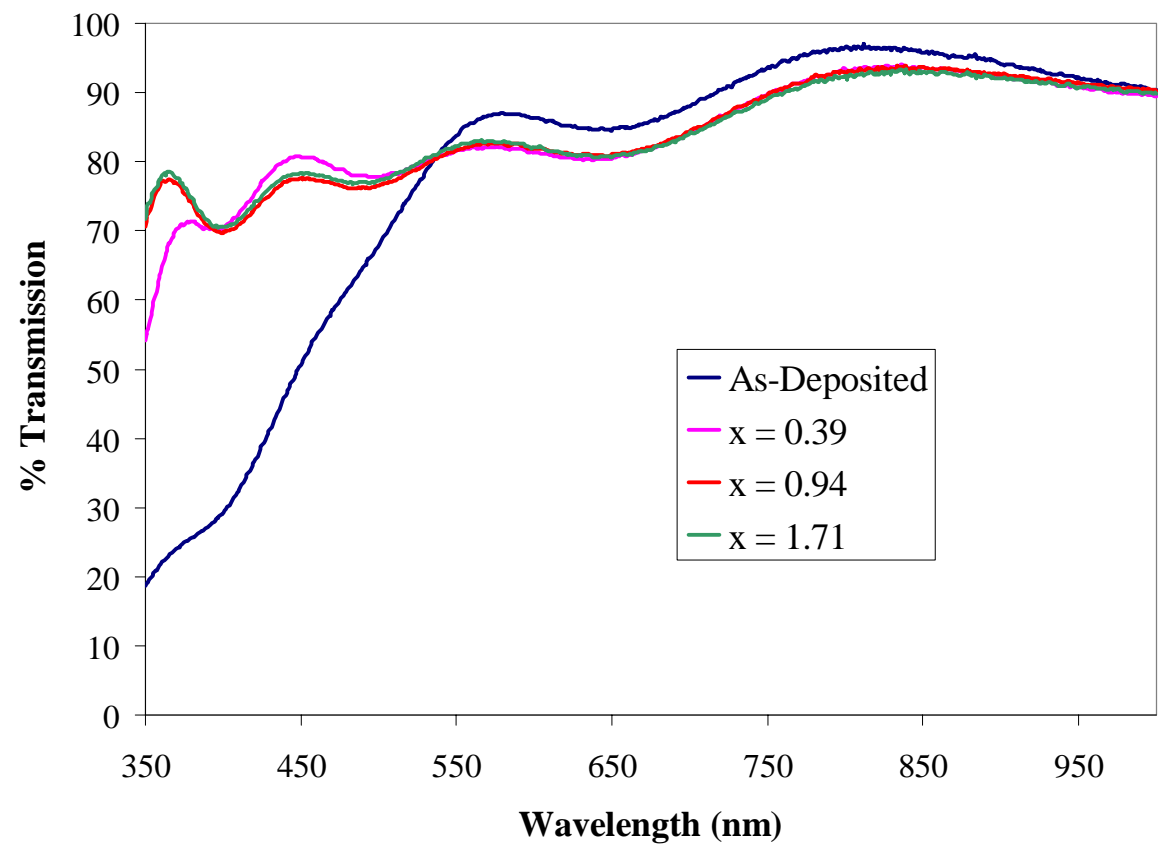

Figure 6: Change in transmission of $\mathrm{Li}_{\mathrm{x}} \mathrm{V}_{2} \mathrm{O}_{5}$ as a function of intercalation extent.

Similarly to the $\mathrm{WO}_{3}$ films, films of $\mathrm{V}_{2} \mathrm{O}_{5}$ were examined for reversibility over 20 cycles. Figure 7 shows the current response of these films to a $50 \mathrm{mV} / \mathrm{second}$ sweep rate between +1.0 and -1.0 Volts. The constant shape of these curves indicates no change in performance from one cycle to the next.

Here again this study has shown the feasibility of producing vanadium oxide storage layers for electrochromic devices by PECVD. High growth rates of $\sim 50 \mathrm{~nm} / \mathrm{min}$ produced films with excellent properties for a storage layer. High transmission was observed in the clear state, and a large storage capacity has been measured. 


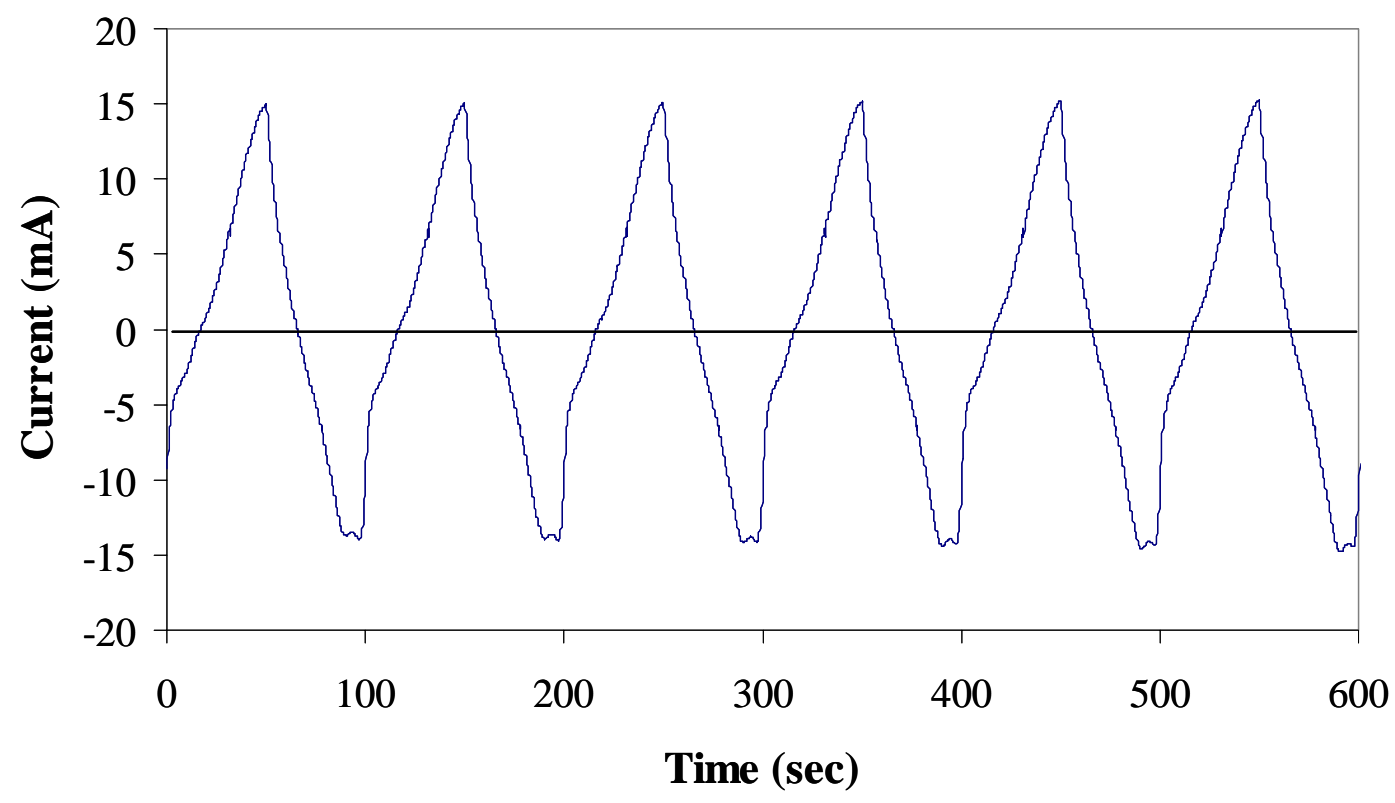

Figure 7: The response of the V2O5 films over several cycles between $-1.0 \mathrm{~V}$ and $+1.0 \mathrm{Volts}$

\section{$\underline{\text { 3. Low-Temperature Deposition of Transparent Electrodes }}$}

Transparent conducting oxides (TCOs) act as the electrical contacts on each side of the electrochromic device. The important characteristics of these layers for this application are high visible transmission and low sheet resistance. Traditionally tin doped indium oxide (ITO) is deposited using sputtering techniques for processes requiring low temperature such as polymer substrates. As a possible alternative we investigated depositing gallium doped zinc oxide (ZnO:Ga) by PECVD. We set a goal of depositing $\mathrm{ZnO}$ :Ga with a sheet resistance of $<100 \Omega /$ sq and $>85 \%$ transmission at reduced temperatures.

We first varied previous results in CMD's PECVD chamber. Diethyl zinc (DEZ) and trimethyl gallium (TMG) were used as precursors. It was found that high $\mathrm{O}_{2}$ :DEZ ratios (>8:1) are required to grow conducting films. Also we verified that a DEZ:TMG ratio of 4:1 maximizes the free electron concentration due to Ga doping and thus yield the highest conducting films. Three sets of experiments were performed to examine the effects of individual parameters and interactions on film properties. Pressure, rf power, electrode gap, total flowrates, and substrate temperature were examined as variable parameters.

Figure 8 shows that conductivity decreases exponentially with temperature. This trend was found to be true at all deposition conditions. Plasma deposition is a highly complex system for oxide deposition, and the results of the experiments show that growth rates and electrical properties were affected by interactions among all of the parameters tested. Figure 9 is a overview representation of the findings for $\mathrm{ZnO}: \mathrm{Ga}$ conductivity versus a variety of parameter changes. All results in Figure 9 were at a substrate temperature of $245^{\circ} \mathrm{C}$. Our best conductivity result was $530 \mathrm{~S} / \mathrm{cm}$ (resistivity $=1.9 \times 10^{-3}$ 
$\Omega \mathrm{cm}$ ) with a growth rate of $23 \mathrm{~nm} / \mathrm{min}$. This would result in a sheet resistance of 19 $\Omega /$ square for a $1 \mu \mathrm{m}$ thick film. This result is comparable to commercially available $\mathrm{SnO}_{2}: \mathrm{F}(\sim 9 \Omega$ /square at $1 \mu \mathrm{m})$ commonly used for devices on glass. Under the same conditions with a substrate temperature of $200{ }^{\circ} \mathrm{C}$ the conductivity was $118 \mathrm{~S} / \mathrm{cm}$ (resistivity $=8.5 \times 10^{-3} \Omega \mathrm{cm}$ ). All films from this study had excellent transmission. A the visible spectra is given for a $600 \mathrm{~nm}$ thick film in Figure 10.

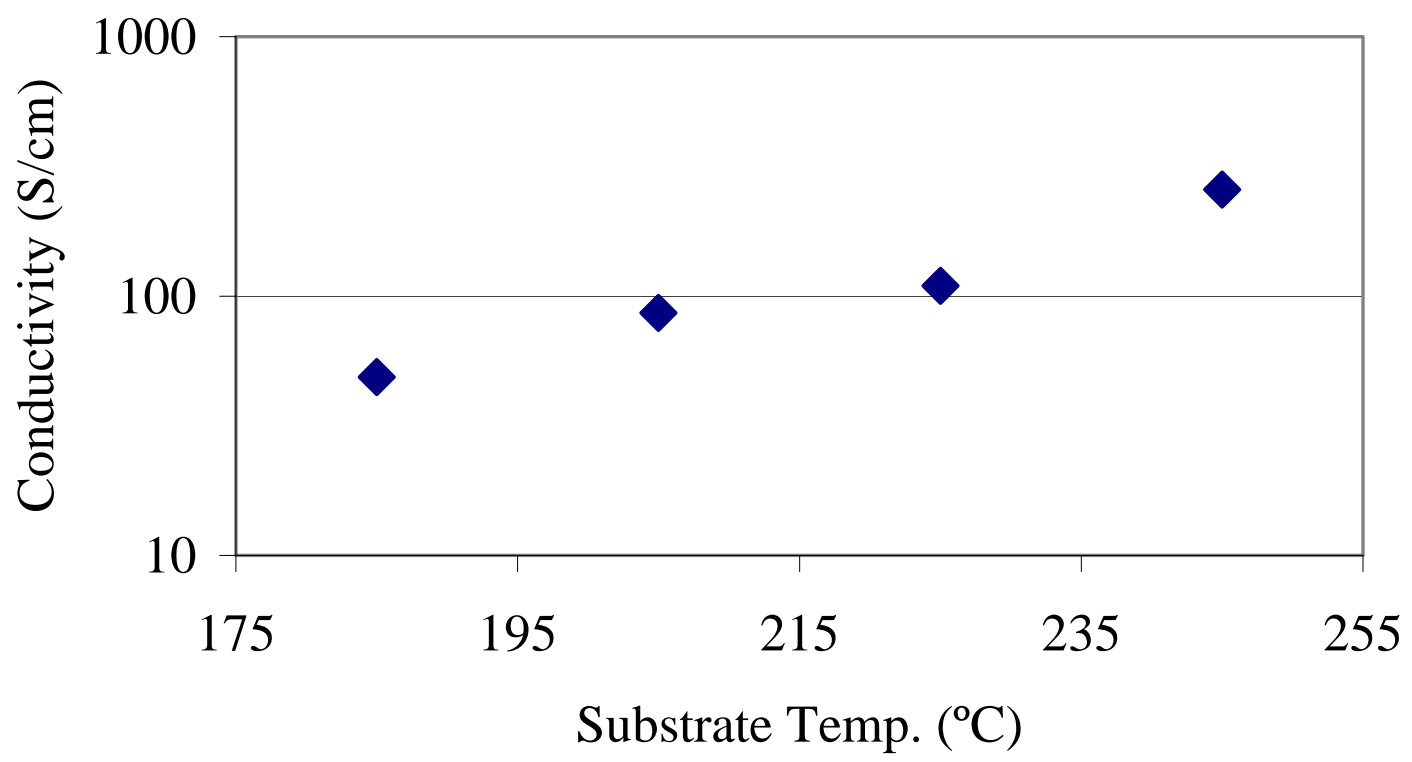

Figure 8: Conductivity of $\mathrm{ZnO}$ :Ga versus substrate temperature.

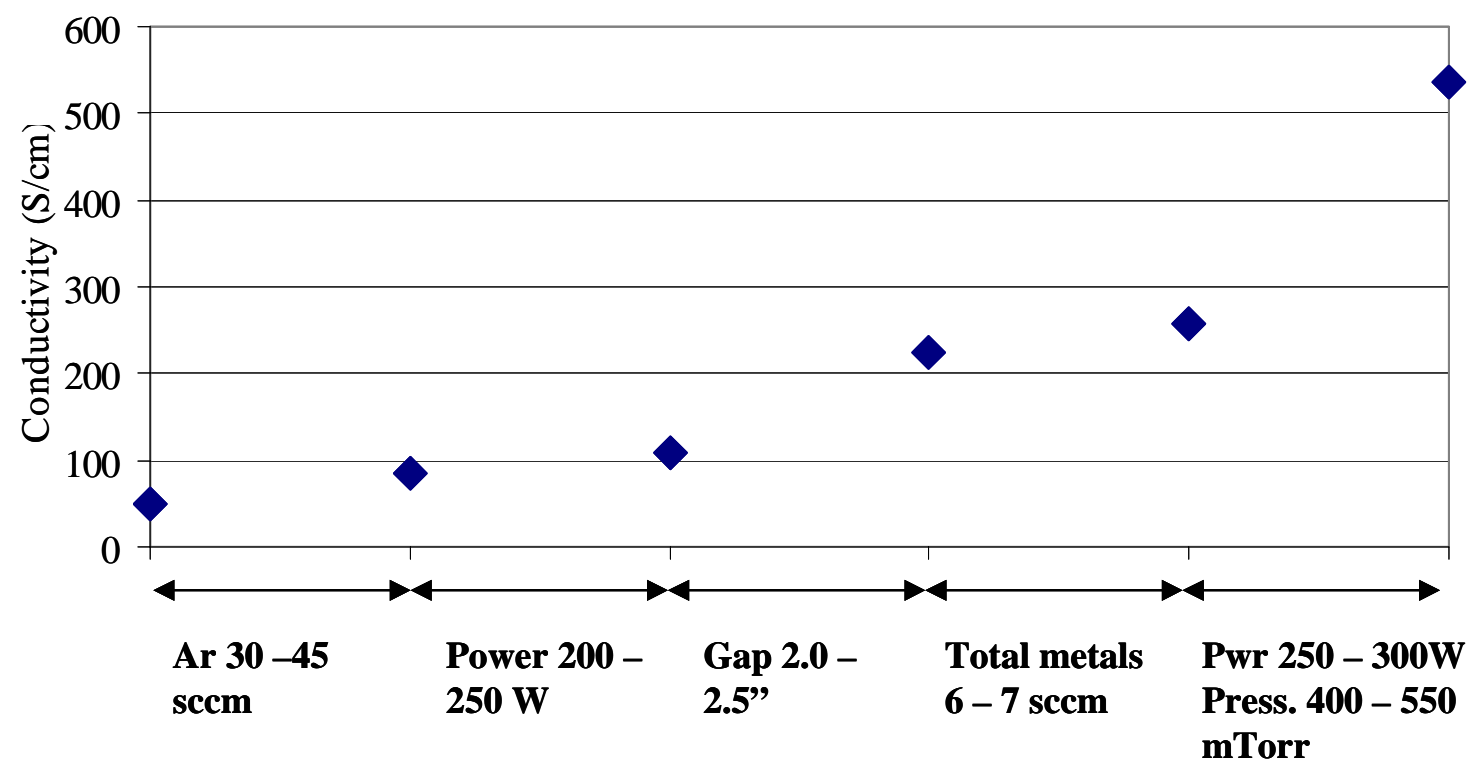

Figure 9: Overview of conductivity results for all sets of experiments. 


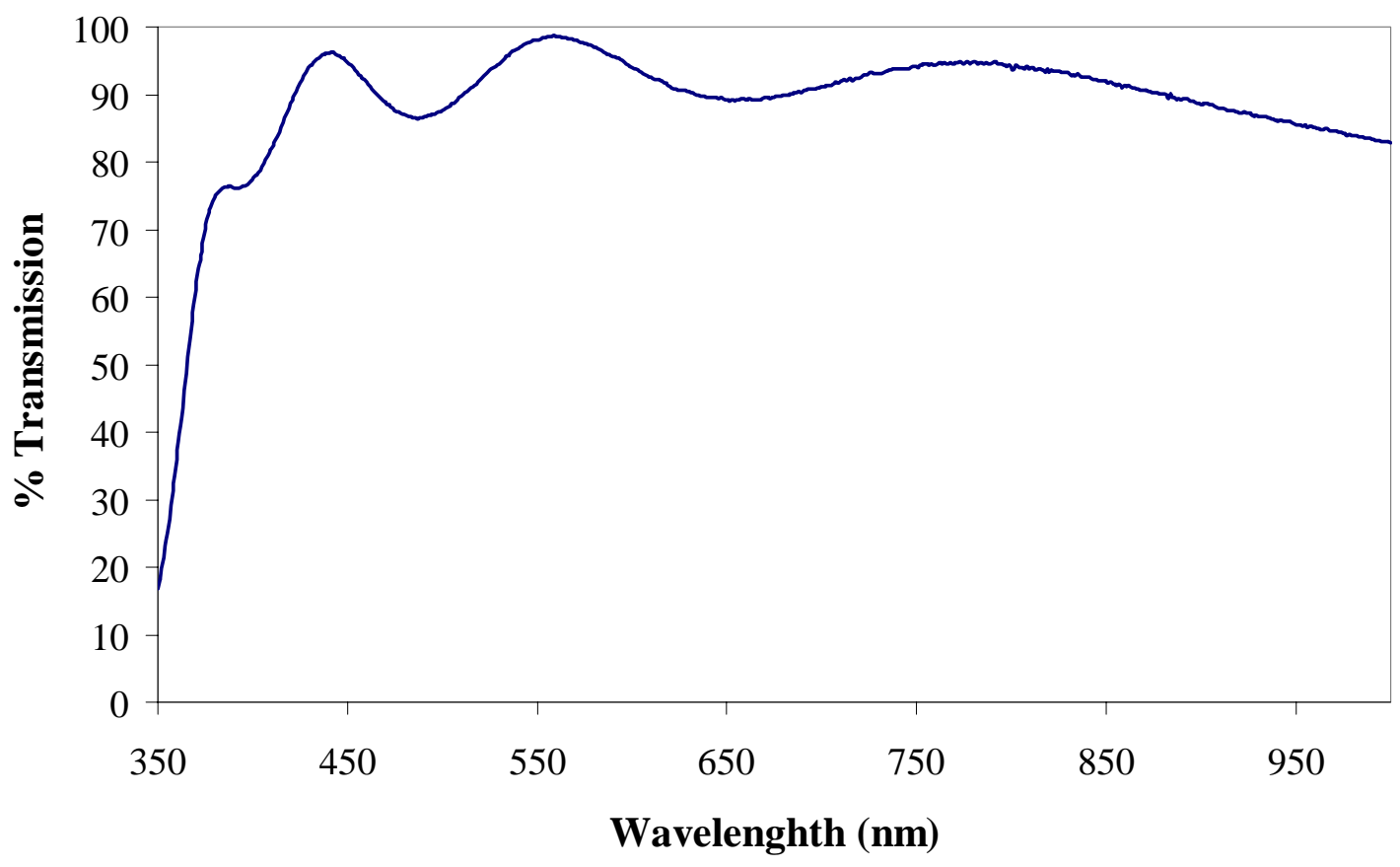

Figure 10: Transmission of a $600 \mathrm{~nm} \mathrm{ZnO:Ga} \mathrm{sample.}$

A significant issue was encountered when we attempted to deposit $\mathrm{ZnO}: \mathrm{Ga}$ on polymers. The minimum temperature for sufficiently conducting films was $200{ }^{\circ} \mathrm{C}$. Because the substrate was inverted, the polymer films would not make uniform contact with the top electrode due to expansion and deformation upon heating. This issue made temperature control difficult and produced non-uniform films with lower than desired conductivity. Several attempts were made to alleviate this issue, such as clamps, tapes and glues, but no solutions were found. Because of this issue we had to abandon the goal of depositing electrochromic stacks on polymers for this stage of the project.

We investigated PECVD as an alternative to sputtering processes for deposition of contact layers for low temperature electrochromic devices. Although many improvements at reduced temperatures were made, the conductivities were $\sim 1 / 2$ of commercially available $\mathrm{SnO}_{2}: \mathrm{F}$ and $\sim 1 / 3$ of those produced by a quality ITO sputting processes. Additionally to achieve these levels of conductivity, the growth rate must maintained at low levels of approximately $25 \mathrm{~nm} / \mathrm{min}$. Also this process would require elevated deposition temperatures, while all the other oxides in our electrochromic stack can be deposited at room temperature. The elevated temperatures $\left(\sim 200^{\circ} \mathrm{C}\right)$ will limit the choice of polymers available for use as substrates and increase the difficulty of full-scale chamber design. These findings lead us to conclude that PECVD of the contact layers is not a viable alternative to sputtering at this time. 


\section{Deposition of Electrolyte Layer}

During this project, a particular challenge has been the deposition of the solidstate electrolyte layer. In particular, maintaining consistent flow rates of the tantalum ethoxide $\left(\mathrm{Ta}\left(\mathrm{OCH}_{2} \mathrm{CH}_{3}\right)_{5}\right)$ precursor for plasma deposition has been a challenge. The precursor has a significantly reduced vapor pressure compared to the other systems and must be heated to $140^{\circ} \mathrm{C}$ to achieve reasonable delivery rates. As a consequence, all lines downstream from the precursor must be maintained above $140^{\circ} \mathrm{C}$ to avoid condensation. Additionally, the precursor vapor pressure is an exponential function of temperature and slight deviations from the $140^{\circ} \mathrm{C}$ set point can cause inconsistent growth rates. Lastly, it has been observed that clogging of the interior lines can cause an overall decreased flow at constant temperature. Presumably, this clogging is due to condensation in the lines and oxidation of the precursor on venting.

To mitigate these concerns, a pressure gauge was installed to monitor the bubble pressure. Clogging of downstream line can be detected by increases in bubbler pressure. Given a bubbler pressure and a fixed precursor temperature the tantalum ethoxide flowrate was estimated from the following equation:

$$
F_{\text {precursor }}=F_{\text {carrier }} \frac{P_{\text {vapor }}}{P_{\text {bubbler }}-P_{\text {vapor }}}
$$

where $F_{\text {precursor }}$ is the flow rate of the tantalum ethoxide, $F_{\text {carrier }}$, the flowrate of the argon carrier gas, $P_{\text {vapor }}$ the vapor pressure of $\mathrm{Ta}\left(\mathrm{OCH}_{2} \mathrm{CH}_{3}\right)_{5}$, and $P_{\text {bubbler }}$, the total pressure in the bubbler. Figure 11 gives the estimated flowrates as a function of bubbler temperature and carrier gas flowrate. This estimation was used as guideline in setting deposition conditions.

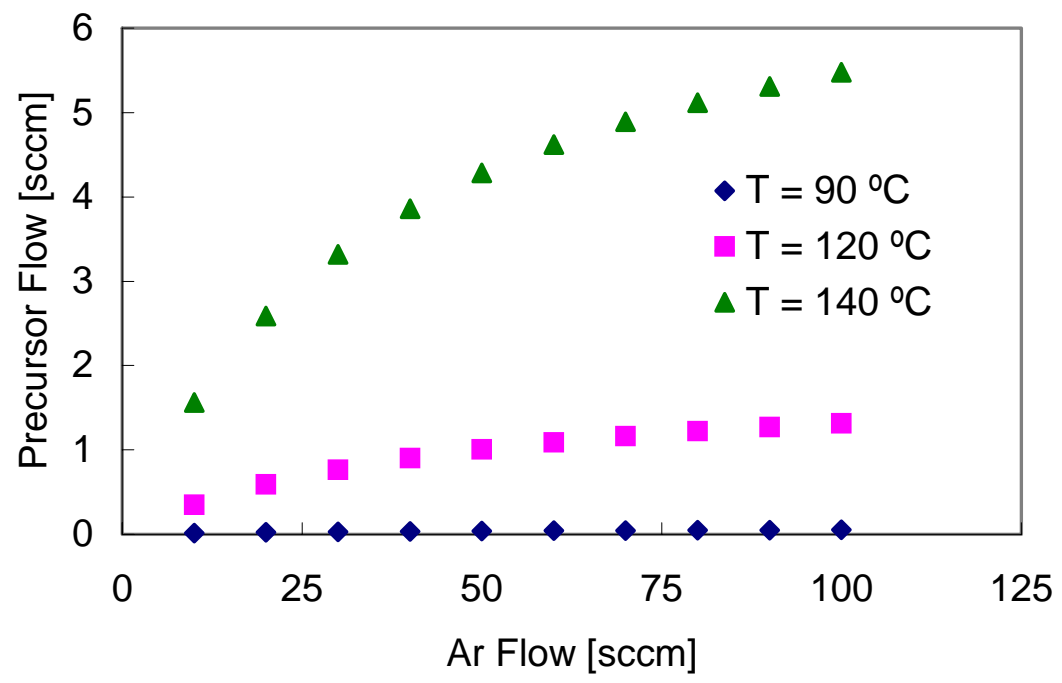

Figure 11: Estimated precursor flow as a function of bubbler temperature and carrier gas flow. 
To determine the best tantalum oxide deposition conditions a series of experiments varying substrate temperature, oxygen flow, and power was performed. Figure 12 summarizes the results on the effect of deposition conditions on growth rate. At low power the rate is seen to increase with increased oxygen flow, while at high power the rate decreases with additional oxygen. In all cases the rate was observed to decrease with increased temperature.

To test the ability of lithium ions to move through these films, films were deposited on consistent films of $\mathrm{WO}_{3}$ and TCO substrates. These half stacks were then darkened and cleared in the liquid electrochemical cell. Figure 13 shows the difference in transmission as a function of the different overlying tantalum oxide layers. A tantalum oxide film with good lithium mobility will easily shuttle the ions from dark and clear states, while a less effective layer will demonstrate less overall change in transmission. Intercalation voltages and times were kept consistent for all films. The tantalum oxide films that showed the greatest ionic mobility were all those grown at low temperature. This test does not test the electronic conductivity of the films due to the use of the electrically insulating liquid electrolyte.

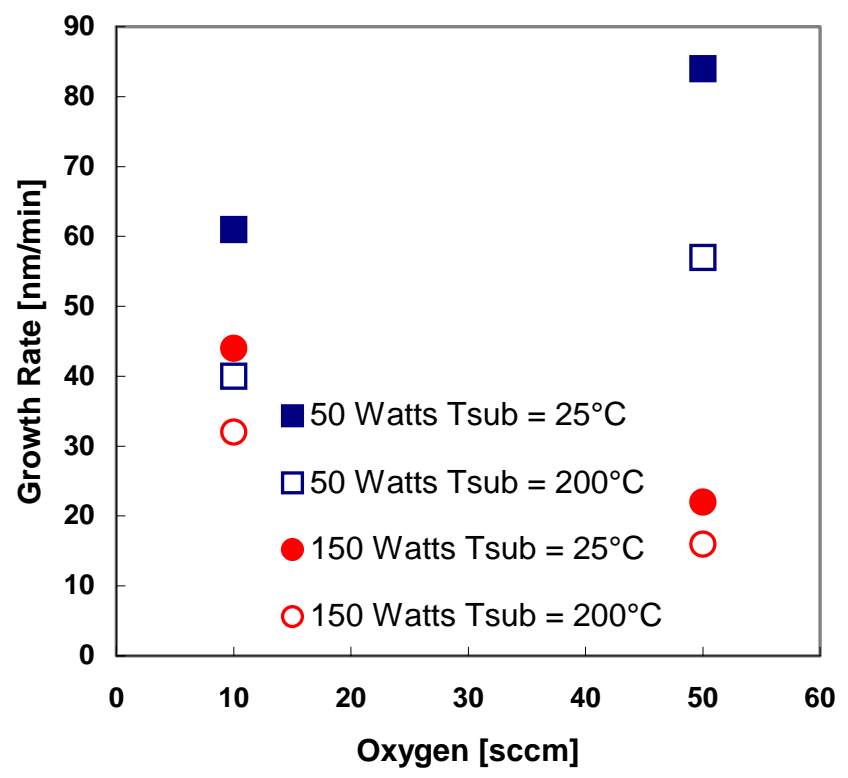

Figure 12: Growth rate of tantalum oxide as a function of deposition conditions 


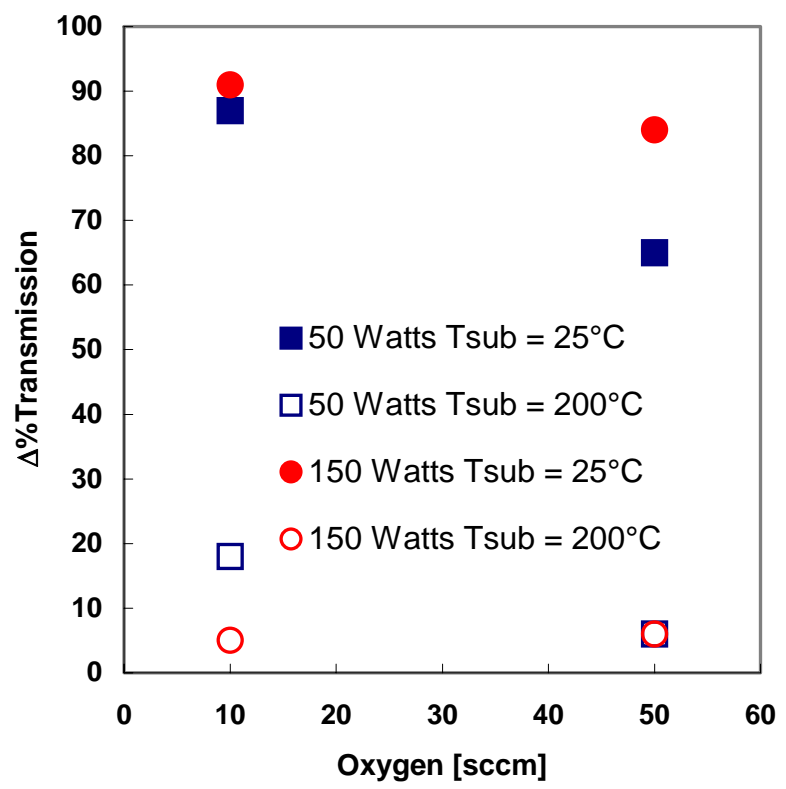

Figure 13: The effect on overall transmission change due to intercalation through the tantalum layers.

Tantalum oxide films must also show electrical resistance. A highly electrically conductive film will not allow a device to switch transmission states. In addition electrical leakage causes gradual self-bleaching. To electrically test the $\mathrm{Ta}_{2} \mathrm{O}_{5}$ films capacitive structures were fabricated for current/voltage (I/V) measurements. Conductive silicon served as a substrate on which tantalum films were grown. The growth conditions for the $\mathrm{Ta}_{2} \mathrm{O}_{5}$ films were the same as those explored in Figures 12 and 13 . Figure 14 shows a representative I/V curve for a $200 \mathrm{~nm}$ thick film grown at room temperature under 1ow $\mathrm{O}_{2}$ and power conditions. This $\mathrm{I} / \mathrm{V}$ curve indicates adequate electrical properties for the tantalum oxide thin film and Table II summarizes several points from figure. The electrical resitivity is calculated from the known current, voltage, thickness, and area. These resistivity values obtained would be sufficient for use in an electrochromic device.

Upon testing of full size devices we observed that the storage and electrochromic layers were shorted in some areas. The shorts were assumed to caused by pin-holes from particles or non-uniformities in the $\mathrm{Ta}_{2} \mathrm{O}_{5}$ layer. Therefore the full devices were made into smaller isolated devices by using $1.5 \mathrm{~mm}$ diameter aluminum dots. Overall the films appear to function well as an electrolyte, but further process development is needed to reduce the spot leakage observed. 


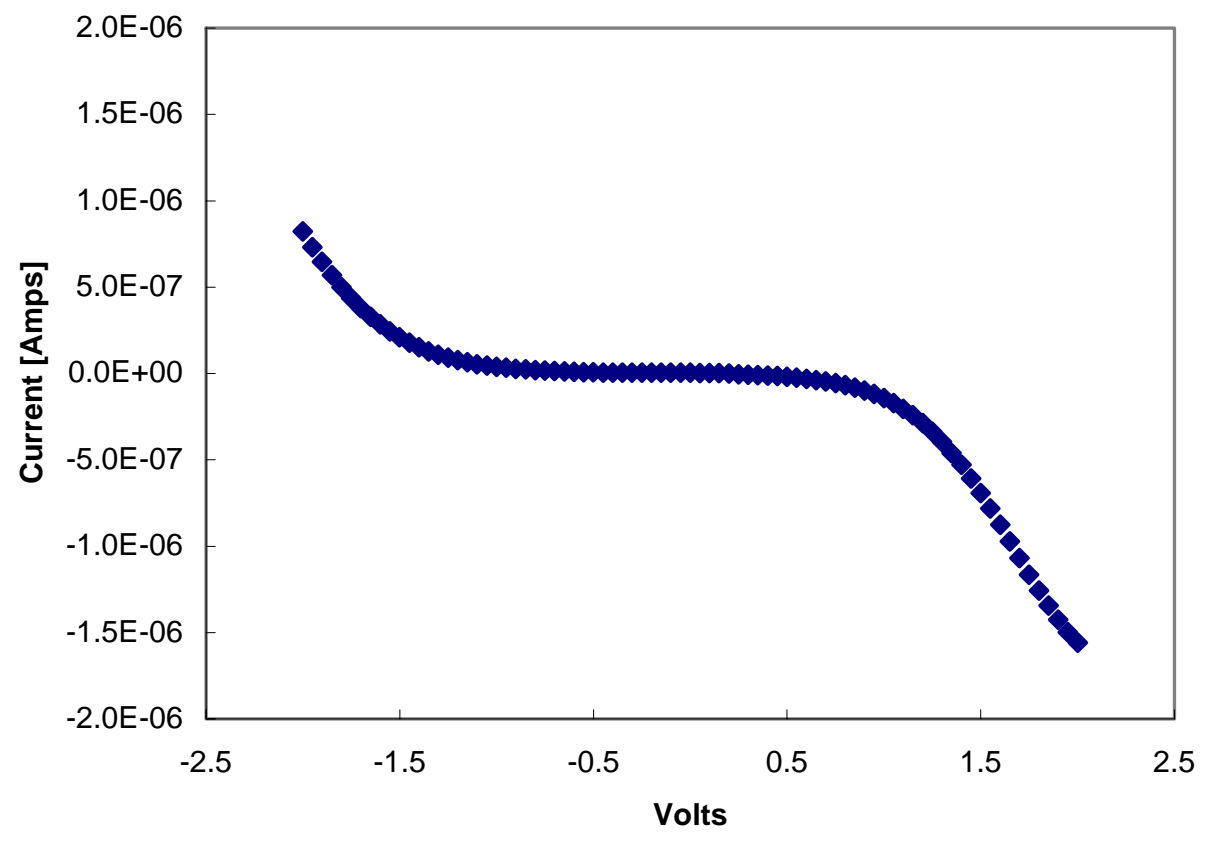

Figure 14: Current/Voltage response of a Ta2O5 film.

\begin{tabular}{|c|c|c|c|c|}
\hline $\begin{array}{c}\mathrm{V} \\
\text { Volts }\end{array}$ & $\begin{array}{c}\mathrm{I} \\
\text { Amps }\end{array}$ & $\begin{array}{c}\mathrm{E} \\
\mathrm{V} / \mathrm{cm}\end{array}$ & $\begin{array}{c}\mathrm{J} \\
\mathrm{A} / \mathrm{cm} 2\end{array}$ & $\begin{array}{c}\rho \\
\text { Ohm-cm }\end{array}$ \\
\hline \hline 2.0 & $-1.6 \mathrm{E}-06$ & 100002 & $8.82 \mathrm{E}-05$ & $1.1 \mathrm{E}+09$ \\
1.5 & $-6.9 \mathrm{E}-07$ & 74992 & $3.92 \mathrm{E}-05$ & $1.9 \mathrm{E}+09$ \\
1.0 & $-1.4 \mathrm{E}-07$ & 49997 & $8.1 \mathrm{E}-06$ & $6.2 \mathrm{E}+09$ \\
0.5 & $-1.9 \mathrm{E}-08$ & 24982 & $1.1 \mathrm{E}-06$ & $2.3 \mathrm{E}+10$ \\
\hline
\end{tabular}

Table II: Calculations of electrical resitivity from results in Figure 12. 


\section{Fabrication and Evaluation of Full Electrochromic Devices}

The final task of this project was to deposit and characterize complete devices. For device fabrication $500 \mathrm{~nm}$ of $\mathrm{WO}_{3}$ was deposited on commercial transparent electrodes. $300 \mathrm{~nm}$ of $\mathrm{Ta}_{2} \mathrm{O}_{5}$ was then deposited, and $\mathrm{Li}^{+}$was inserted in the half device using a liquid cell. This was followed by the deposition of $100 \mathrm{~nm}$ of $\mathrm{V}_{2} \mathrm{O}_{5}$. Due to the pinholes and non-uniformities in the electrolyte layer on large devices, $1.5 \mathrm{~mm}$ diameter aluminum dots were evaporated and used as the top contact.

Figure 15 shows the movement of charge $\left(\mathrm{Li}^{+}\right)$with the application of a $3 \mathrm{~V}$ electric field. For the first 120 seconds the voltage was set a $-3 \mathrm{~V}$ and $\mathrm{Li}^{+}$was pulled into the $\mathrm{WO}_{3}$ layer. At $120 \mathrm{sec}$ the voltage is switched to $+3 \mathrm{~V}$ and $\mathrm{Li}^{+}$was moved into the $\mathrm{V}_{2} \mathrm{O}_{5}$ storage layer. The value of $18 \mathrm{mC} / \mathrm{cm}^{2}$ corresponds to an intercalation extent of $\mathrm{x}=$ 0.16 in $\mathrm{WO}_{3}$. Because of the small size of these devices, we were not able to collect the change in optical properties for these devices, but an estimation can be made using the charge and Figure 2. Additionally the films were cycled from $-3 \mathrm{~V}$ to $+3 \mathrm{~V}$ for 30 minutes. Figure 16 provides the results for 1000 seconds of this test. Very little change was observed of the entire cycling time. These tests confirm that the working oxides $\left(\mathrm{V}_{2} \mathrm{O}_{5} / \mathrm{Ta}_{2} \mathrm{O}_{5} / \mathrm{WO}_{3}\right)$ we producing by PECVD are stable and have acceptable switching times.

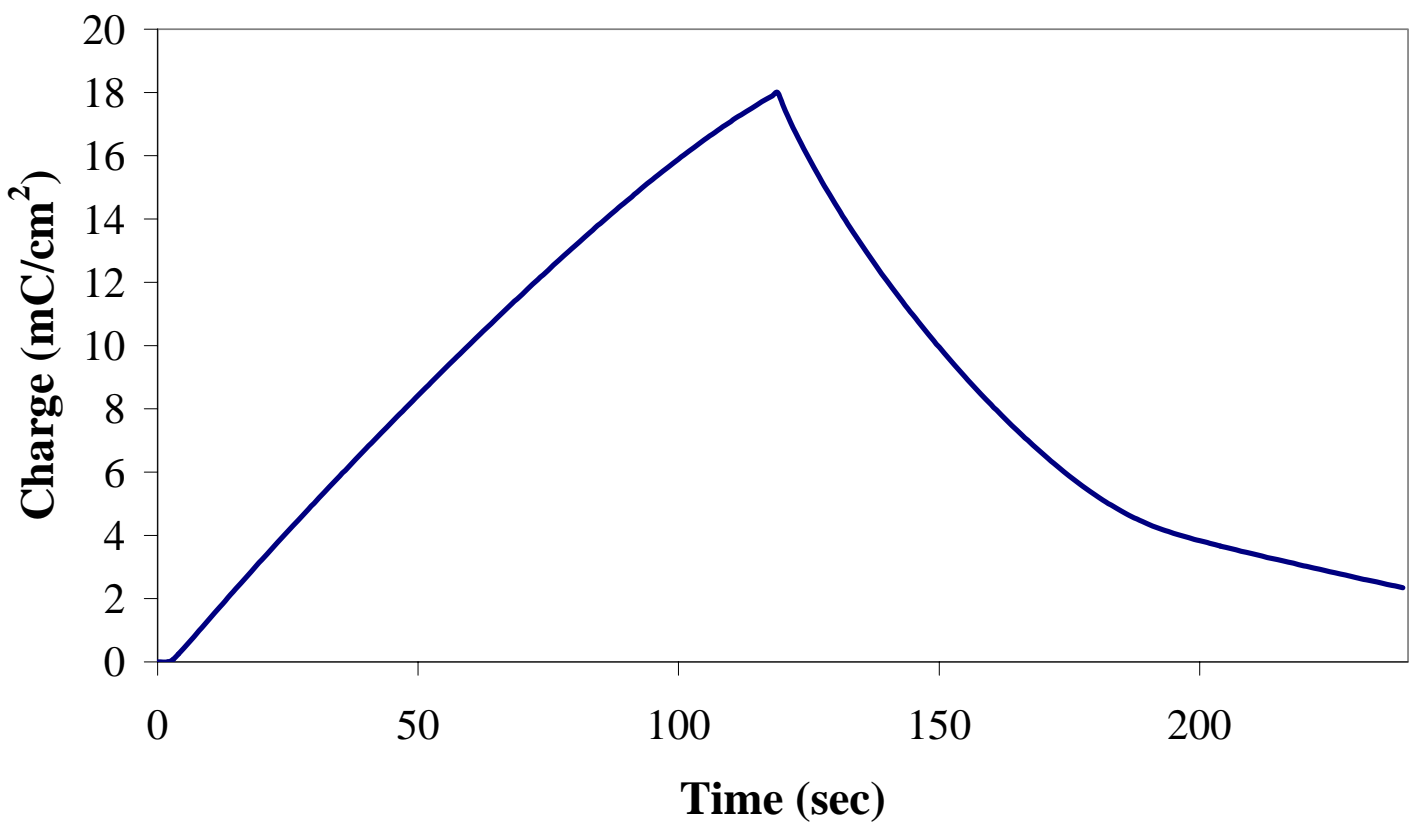

Figure 15: Charge versus time: $-3 \mathrm{~V}$ for first $120 \mathrm{sec},+3 \mathrm{~V}$ for the next $120 \mathrm{sec}$. 


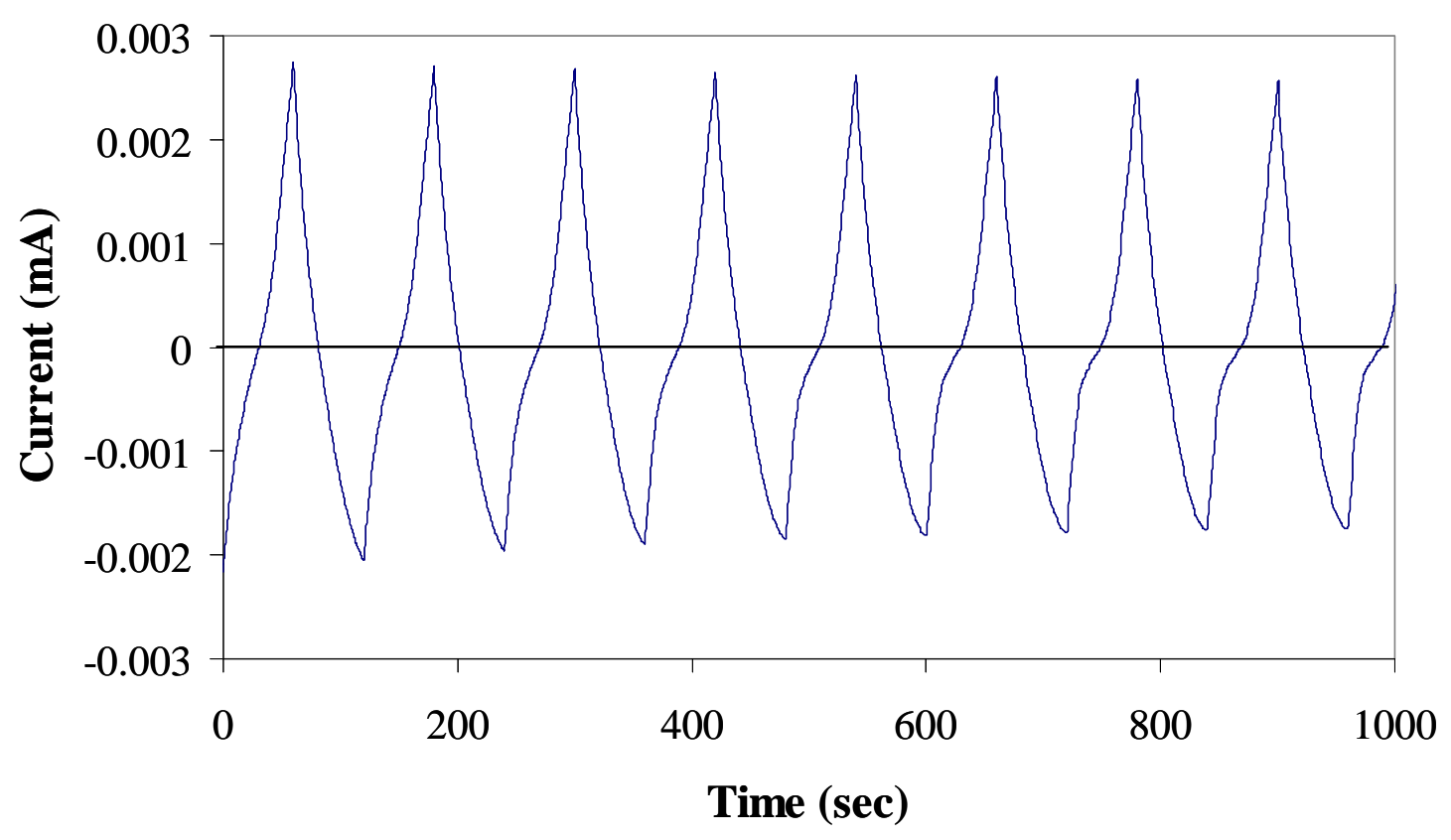

Figure 16: Current response to the cycling of small $1.5 \mathrm{~mm}$ devices from $-3 \mathrm{~V}$ to $+3 \mathrm{~V}$ at steps of $100 \mathrm{mV} / \mathrm{sec}$.

To quantify the visible transmission on larger devices (1 1/2 “ $\mathrm{x} 2$ ”) a different electrolyte was used. A polymer based solid electrolyte was made using polymethlmethacrylate (PMMA). To make the electrolyte PMMA was dissolved in ethyl-acetate, and the resulting solution was mixed with 1 molar $\mathrm{LiClO}_{4} /$ propylene carbonate, which acts as an electrolyte. Several drops of this solution were placed on intercalated $\mathrm{V}_{2} \mathrm{O}_{5}$ films on glass. This was then pressed against an as-deposited $\mathrm{WO}_{3}$ film on glass. Finally the stack was baked at $\sim 80^{\circ} \mathrm{C}$ to evaporate the ethyl-acetate, forming a solid cell, shown in Figure 17. Transmissions of the devices in various states are given in Figure 18. The thickness of the PECVD deposited $\mathrm{V}_{2} \mathrm{O}_{5}$ and $\mathrm{WO}_{3}$ were 100 $\mathrm{nm}$ and $400 \mathrm{~nm}$ respectively. The average visible $(400-800 \mathrm{~nm})$ clear state transmission was $69 \%$ and the dark transmission was $11 \%$.

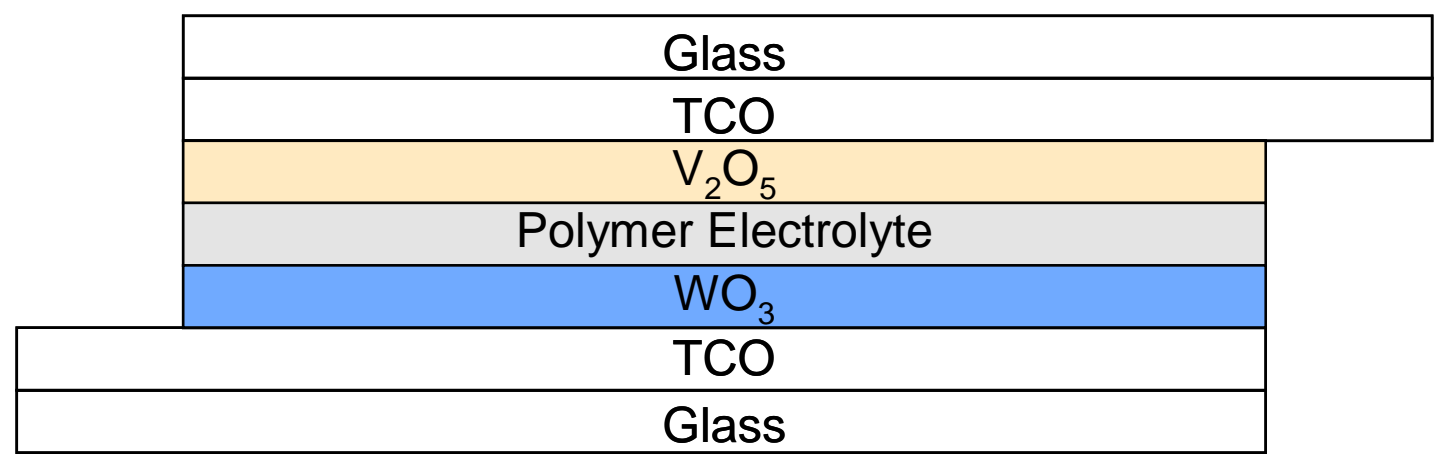

Figure 17: Schematic of the solid-state polymer device. 


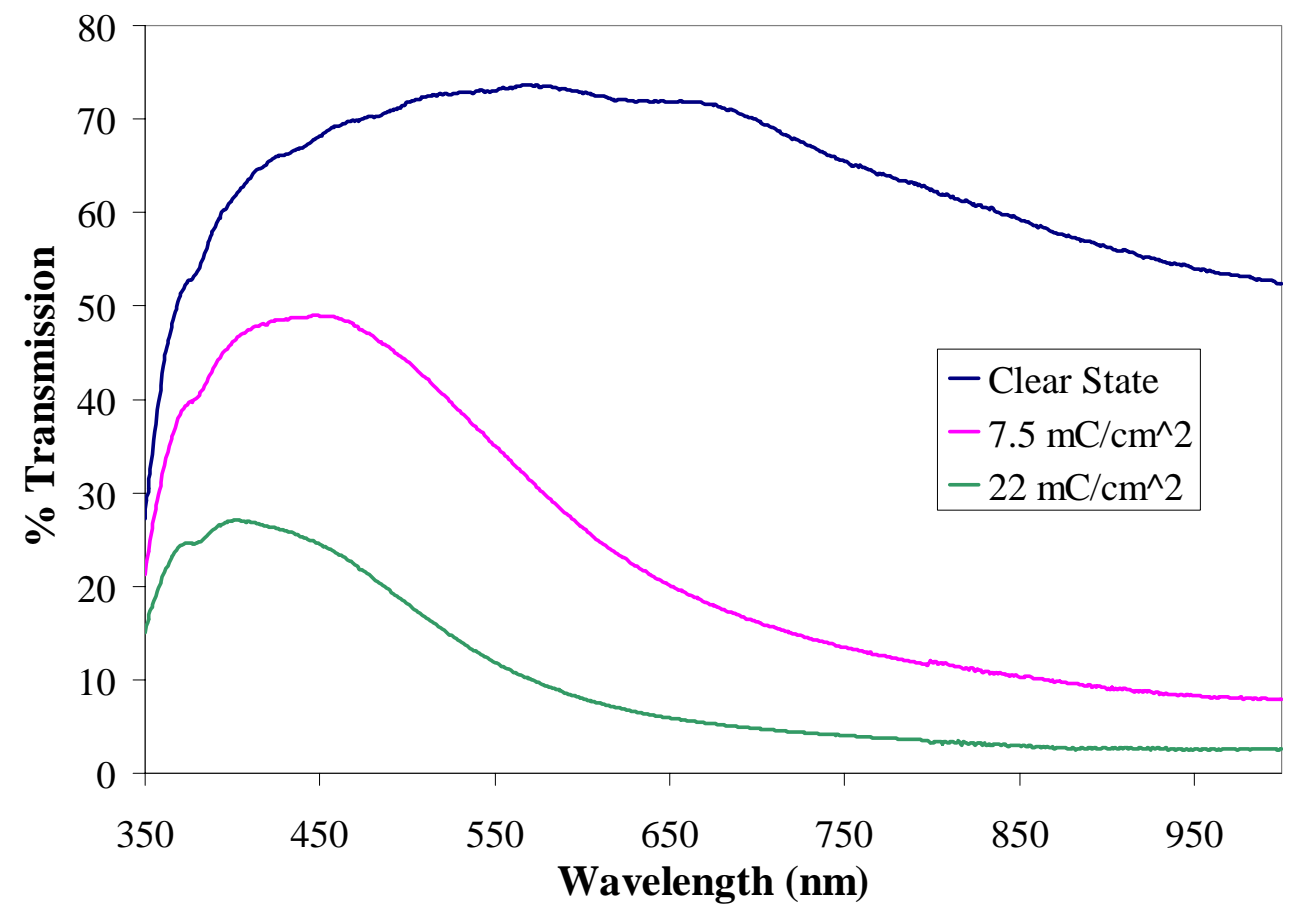

Figure 18: Transmission of a full device with the polymer electrolyte versus intercalation extent.

\section{Summary and Conclusions}

We have successfully deposited all of the films necessary for a complete electrochromic devices using PECVD. The electrochromic layer, $\mathrm{WO}_{3}$, displayed excellent change in visible transmission with good switching times. The storage layer, $\mathrm{V}_{2} \mathrm{O}_{5}$, exhibited a high storage capacity and good clear state transmission. The electrolyte, $\mathrm{Ta}_{2} \mathrm{O}_{5}$, was shown to functional with good electrical resistivity to go along with the ability to transfer $\mathrm{Li}$ ions. There were issues with leakage over larger areas, which can be address with further process development. We developed a process to deposit $\mathrm{ZnO}$ :Ga with a sheet resistance of $<50 \Omega /$ sq. with $>90 \%$ transmission. Although we were not able to deposit on polymers due to the temperatures required in combination with the inverted position of our substrates.

Two types of full devices were produced. Devices with $\mathrm{Ta}_{2} \mathrm{O}_{5}$ were shown to be functional using small aluminum dots as the top contact. The polymer electrolyte devices were shown to have a clear state transmission of $69 \%$ and a darkened state transmission $11 \%$. These un-optimized devices compare well with commercially available products 
offered by Sage Electrochromics, Inc., which have a stated clear transmission of 59\% and dark transmission of $4 \%$.

Several advantages of oxides grown by PECVD were displayed in this project. The first advantage is deposition rates were significantly higher than typical sputtering rates. Rates of $100 \mathrm{~nm} / \mathrm{min}$ were achieved for $\mathrm{WO}_{3}$, and rates of $50 \mathrm{~nm} /$ min produced quality $\mathrm{V}_{2} \mathrm{O}_{5}$ and $\mathrm{Ta}_{2} \mathrm{O}_{5}$ films. Faster rates will produce a significant reduction in cost due to higher throughput. Another advantage was that films were less dense than those produced by sputtering as reported in the literature. This leads to high diffusion coefficients and fast switching times. Diffusion coefficients of $7 \times 10^{-10}$ and $7 \times 10^{-12}$ $\mathrm{cm}^{2} / \mathrm{sec}$ have been measured for $\mathrm{WO}_{3}$ and $\mathrm{V}_{2} \mathrm{O}_{5}$ respectively. Also less dense films have been shown to produce larger contrast ratios in $\mathrm{WO}_{3}$ and larger storage capacity in $\mathrm{V}_{2} \mathrm{O}_{5}$.

It is our conclusion from the data collected in this category 1 project, that the use of PECVD for the deposition of the working layers in an electrochromic device is feasible and advantageous from an economic and device functionality standpoint when compared to sputtering. These results and the lessons learned can be applied toward deposition on polymers and equipment scale-up in future work. 